\title{
Ten-year narrative review on antimicrobial resistance in Singapore
}

\author{
Alvin Qijia $\underline{C h u a}^{1,2}$, BSc, MSc, Andrea Lay-Hoon $\underline{K w a}^{1,3}$, PharmD, Thean Yen $\underline{T a n}^{3,4}$, MBBCh, MRCPath, \\ Helena Legido-Quigley ${ }^{2}$, PhD, MSc, Li Yang $\underline{\mathrm{Hsu}}^{2,5}, \mathrm{MBBS}, \mathrm{MPH}$
}

\begin{abstract}
Antimicrobial resistance (AMR) results in drug-resistant infections that are harder to treat, subsequently leading to increased morbidity and mortality. In 2008, we reviewed the problem of AMR in Singapore, limiting our discussion to the human healthcare sector. Ten years later, we revisit this issue again, reviewing current efforts to contain it in order to understand the progress made as well as current and emerging challenges. Although a significant amount of work has been done to control AMR and improve antibiotic prescribing in Singapore, most of it has focused on the hospital setting, with mixed impact. The role of antibiotic use and AMR in food animals and the environment - and the link to human health - is better understood today. This issue of AMR encompasses both human health as well as animal/food safety, and efforts to control it will need to continually evolve to maintain or improve on current gains.
\end{abstract}

Keywords: anti-bacterial agents/therapeutic use, antimicrobial stewardship, bacterial drug resistance, public health, Singapore

\section{INTRODUCTION}

Antimicrobial resistance (AMR), which results in drug-resistant infections that are harder to treat and attendant increased morbidity and mortality, is a slow but implacable evolutionary process that has been sped up by human activity in multiple sectors, particularly human health and agriculture. ${ }^{(1-4)}$ In 2008, when the issue was less well known, we wrote a position paper on the problem of AMR in Singapore, limiting our discussion to the human healthcare sector. ${ }^{(5)}$

Several recommendations, as summarised in Table I, were made based on evidence and expert opinion available a decade ago that would facilitate the prudent and appropriate use of antibiotics. ${ }^{(5)}$ These included hospital- and ministry-level policies and interventions that resulted in enhanced surveillance, formal antimicrobial stewardship programmes (ASPs) in hospitals, and education on AMR. ${ }^{(5)}$ As seen in Table I, we observed that the majority of the recommendations made in $2008^{(5)}$ have been implemented over the past decade in local public sector hospitals, but not in private hospitals or the primary healthcare sector. All acute care public sector hospitals now have ASPs - primarily funded by the Ministry of Health $(\mathrm{MOH})$ - and formal laboratory surveillance of key antibiotic-resistant bacteria isolated from patients attending public sector hospitals. Teaching of AMR to healthcare professionals and undergraduates is also increasingly emphasised.

Understanding of AMR has broadened, particularly with regard to the role of agriculture and the environment. ${ }^{(1-4)}$ After ten years, it is timely that the issue of AMR and efforts to contain it in Singapore be reviewed again, in order to understand the progress made and the challenges that remain or have emerged over time.
AWARENESS AND POLICY-SETTING GOALS

Unlike a decade ago, AMR is widely recognised as a global public health threat today. ${ }^{(1-4)}$ The threat of a post-antibiotic era 'doomsday scenario', where common infections or minor injuries can result in death, has been raised by the World Health Organization (WHO). ${ }^{(1)}$ The United Kingdom's Review on AMR estimated that by 2050, the continued rise in AMR could result in ten million deaths annually and an economic loss of USD 100 trillion. ${ }^{(2)}$ This is corroborated by a separate World Bank report conducted in 2016, which estimated that the impact of AMR would mirror that of the 2008 global financial crisis by 2050.(6)

In response, the World Health Assembly adopted a Global Action Plan for AMR in 2015, calling on each member state to develop and implement a corresponding context-specific multisectoral national plan. ${ }^{(3)}$ In the following year, at a special high-level meeting of the United Nations General Assembly, all member states pledged to dedicate themselves to a global response against this rising threat, adopting a 'One Health' approach. ${ }^{(4)}$

In line with this goal, Singapore launched its own National Strategic Action Plan on AMR in November 2017. (7) The multisectoral plan, which was jointly developed by the $\mathrm{MOH}$, the former Agri-Food and Veterinary Authority of Singapore (AVA), the National Environment Agency (NEA), and the national water agency $P \cup B$, sets a national 'One Health' framework to reduce the emergence and spread of drug-resistant micro-organisms through five core strategies: (a) surveillance and risk assessment, to enable timely and appropriate responses to be mounted; (b) research, to better understand AMR and provide information - where gaps in evidence exist - to

${ }^{1}$ Department of Pharmacy, Singapore General Hospital, ${ }^{2}$ Saw Swee Hock School of Public Health, National University of Singapore, ${ }^{3}$ Duke-NUS Medical School, National University of Singapore, ${ }^{4}$ Department of Laboratory Medicine, Changi General Hospital, ${ }^{5}$ National Centre for Infectious Diseases, Singapore

Correspondence: A/Prof Li Yang Hsu, Head, Infectious Diseases Programme, Saw Swee Hock School of Public Health, National University of Singapore, 12 Science Drive 2, Singapore 117549. mdchly@nus.edu.sg 
Table I. Recommendations made in $\mathbf{2 0 0 8}$ to reduce inappropriate antimicrobial usage and an assessment of their implementation over the past decade.

\begin{tabular}{l}
\hline Recommendations \\
\hline General \\
Closing local data gaps in antimicrobial prescription and \\
antimicrobial resistance (AMR), including:
\end{tabular}

(a) Antimicrobial prescription data from the private and primary healthcare sectors.

(b) AMR data from the community and private hospitals.

(c) Cost-effectiveness of different interventions for facilitating appropriate antibiotic use in the local framework.

(d) Patients' and healthcare providers' perceptions of antimicrobial prescription.

(e) Impact of the pharmaceutical industry's actions on physician prescribing.

Continued and improved surveillance and antimicrobial stewardship, with more focus on standardising definitions and communicating results and insights across institutions.

\section{Regulators}

The $\mathrm{MOH}$ should take a more active and positive role in regulating antibiotic usage.

(a) Enforce the establishment of antibiotic stewardship programmes (ASPs) in all hospitals, as with infection control programmes.

(b) Award funding to public sector hospitals for ASPs in proportion to the savings from public healthcare subsidies.

(c) Facilitate the sharing of laboratory and prescription data from private and public laboratories and pharmacies for surveillance purposes.

(d) Re-examine the current situation where general practitioners and private specialists may have a financial incentive to prescribe more and expensive antibiotics.

(e) Support research or quality improvement projects on finding effective ways of improving antibiotic prescription at healthcare facilities.

(f) Coordinate collaborative work among public and private hospitals in improving antimicrobial stewardship.

(g) Track prescribing practices at hospitals through standardised and agreed metrics in the form of process and outcome measures, e.g. Clostridium difficile rates, AMR rates and drug usage.

(h) Regulate the interactions between pharmaceutical industries and doctors, in particular promoting stringent disclosure requirements and restrictions as proposed internationally.

(i) Promote the use of healthcare information technology (e.g. computerised surveillance and computerised decision support systems) to help improve prescription practices.

The $\mathrm{MOH}$ can support local and/or regional research in the development of new antimicrobial agents.

\section{State of implementation}

Antimicrobial prescription data from private and primary healthcare sectors is not easily accessible nor compiled with public sector data.

AMR data from community hospitals and private hospitals is available at institutional level but not compiled or shared at the national level.

Cost-effectiveness of different interventions is not well worked out.

Patients' and healthcare providers' perceptions of antimicrobial prescription have been captured in a series of small studies.

The impact of the pharmaceutical industry's actions on prescribing has been evaluated overseas.

The formation of the National Antimicrobial Resistance Control Committee's National Antimicrobial Stewardship Expert Panel by the Ministry of

Health $(\mathrm{MOH})$ has resulted in improved surveillance in public sector acute hospitals, as well as better support for antimicrobial stewardship and communication of results and insights between public sector hospitals.

ASPs are now established in all public sector acute hospitals and some community hospitals, although not in private hospitals.

Funding has been made available to public sector acute hospitals for the establishment and maintenance of ASPs.

Laboratory and prescription data from the public healthcare sector is now collated by the National Antimicrobial Resistance Control Committee (NARCC) for surveillance purposes. Private hospital and laboratory data remains largely unavailable for such purposes.

This has not been re-examined.

More research has been performed and research funding made available for these purposes.

This has not been addressed.

For public sector acute hospitals, this has now been standardised under NARCC.

No new regulations have been established regarding interactions between pharmaceutical industries and doctors, but self-regulation, to a large part, has occurred.

Healthcare information technology has been deployed at some public sector acute hospitals to assist in both surveillance and prescription of antibiotics.

Different research institutions have conducted research on discovering and/ or developing new antimicrobial agents, although none have yet reached the stage of clinical trials. 
Table I. $($ Contd...)

\begin{tabular}{|c|c|}
\hline Recommendations & State of implementation \\
\hline \multicolumn{2}{|l|}{ Hospitals } \\
\hline $\begin{array}{l}\text { Hospital administrators and leaders should actively support } \\
\text { ASP efforts. This is critical to the success of ASPs. }\end{array}$ & Public sector hospital leaders are now generally strong supporters of ASPs. \\
\hline $\begin{array}{l}\text { Hospitals should provide administrative and financial } \\
\text { support for and recognition of multidisciplinary ASPs. } \\
\text { Such programmes should be recognised as being part } \\
\text { of an overarching attempt to limit AMR and nosocomial } \\
\text { infections. Therefore, the role of infection control efforts in } \\
\text { this area should be recognised and supported as well. }\end{array}$ & $\begin{array}{l}\text { These efforts are now well supported in most public sector acute hospitals but } \\
\text { not yet in private hospitals. }\end{array}$ \\
\hline $\begin{array}{l}\text { Hospital ASPs should collaborate actively with Infection } \\
\text { Control and Pharmaceutical and Therapeutics committees. }\end{array}$ & This has generally been achieved at many public sector hospitals. \\
\hline $\begin{array}{l}\text { ASPs should monitor and audit their work regularly and } \\
\text { improve on their interventions over time. }\end{array}$ & This has generally been achieved at many public sector hospitals' ASPs. \\
\hline \multicolumn{2}{|l|}{ Educators } \\
\hline $\begin{array}{l}\text { At the undergraduate university level, medical and } \\
\text { pharmacy education should be coordinated to give greater } \\
\text { emphasis to appropriate antimicrobial prescription and the } \\
\text { threat of AMR. }\end{array}$ & $\begin{array}{l}\text { This has gradually been implemented over the years, particularly by infectious } \\
\text { disease physicians and pharmacists teaching in local universities. }\end{array}$ \\
\hline $\begin{array}{l}\text { At the postgraduate level, industry-sponsored programmes } \\
\text { should be limited. Professional bodies and societies should } \\
\text { educate on and implement good clinical practices in } \\
\text { antimicrobial usage. }\end{array}$ & $\begin{array}{l}\text { A combination of self-regulation by pharmaceutical industries and local } \\
\text { public sector hospitals has resulted in the limitation of industry-sponsored } \\
\text { programmes associated with antimicrobial agents. Local professional societies } \\
\text { have made attempts to educate healthcare professionals on antimicrobial } \\
\text { usage and resistance. }\end{array}$ \\
\hline $\begin{array}{l}\text { Together with the Health Promotion Board and professional } \\
\text { bodies/societies, the MOH should step up its attempts to } \\
\text { educate the public and physicians regarding appropriate } \\
\text { antibiotic usage. A shift in perception and expectations for } \\
\text { both patients and providers is required in this area. }\end{array}$ & This is now an action item in the National Strategic Action Plan on AMR. \\
\hline \multicolumn{2}{|l|}{ Pharmaceutical industry } \\
\hline $\begin{array}{l}\text { Local and regional branches of pharmaceutical industries } \\
\text { should adopt the Pharmaceutical Research and } \\
\text { Manufacturers of America's updated code of conduct on } \\
\text { interactions with physicians. }\end{array}$ & $\begin{array}{l}\text { The pharmaceutical industry in Singapore is now in compliance with the code } \\
\text { of conduct, particularly in the public sector, where hospitals have imposed } \\
\text { limits on physicians' interactions with the industry. }\end{array}$ \\
\hline
\end{tabular}

support the other core strategies; (c) education, to increase awareness and understanding of AMR; (d) prevention and control of infection, to stop transmission of resistant organisms in healthcare settings and the community; and (e) optimisation of antimicrobial use, to slow the emergence of resistance and minimise healthcare costs.

In July 2018, the WHO released a report on action against AMR at the country level. ${ }^{(8)}$ The report was based on submissions of a country self-assessment questionnaire, summarising national progress on the strategic objectives in the Global Action Plan. ${ }^{(3,9)}$ The topics assessed included human health, animal production, food safety concerns, plant production and the environment. A total of 154 countries were included in the report, showing much international effort to tackle AMR. Singapore was reported to have achieved most of the strategic objectives, especially for human health. ${ }^{(10)}$ Some gaps were identified, including better antibiotic stewardship, surveillance, education and awareness, and research on areas involving animal and plant health, as well as the environment. ${ }^{(10)}$

\section{CHANGES IN ANTIMICROBIAL RESISTANCE EPIDEMIOLOGY OVER A DECADE Global perspective}

The first global surveillance report published by the WHO in 2014 showed high rates of AMR in almost all WHO regions, although updated data is not available from several countries. Asia had the highest rates of third-generation cephalosporin-resistant Enterobacteriaceae. ${ }^{(1)}$ The vast majority of third-generation cephalosporin resistance in Enterobacteriaceae is due to the production of extended-spectrum beta-lactamases (ESBLs) and, to a lesser extent, AmpC beta-lactamases. ${ }^{(11)}$ This is not just a problem within hospitals, as the incidence of ESBL infections is also increasing rapidly in the community setting, with ESBLproducing Enterobacteriaceae faecal colonisation rates among healthy individuals reported at $14 \%$ or higher worldwide. ${ }^{(12,13)}$

The widespread use of carbapenems, largely directed against possible and proven ESBL-producing Enterobacteriaceae infections, likely promoted the selection and subsequent dissemination of multiple different mechanisms of carbapenem 
resistance among Enterobacteriaceae. ${ }^{(14)}$ In South and Southeast Asia, carbapenem-resistant Enterobacteriaceae (CRE) has been reported in virtually every country, possibly exceeding $10 \%$ of all hospital-cultured Enterobacteriaceae in South Asian countries. ${ }^{(15)}$ More recently, transmissible resistance to colistin, one of the few available drugs for treating carbapenem-resistant Gram-negative infections, has also surfaced. Plasmid-mediated mcr (mobilised colistin resistance) genes were first described in Escherichia coli (E. coli) isolated from food animals in China in 2015. They were subsequently found in clinical isolates in various parts of the world, including Singapore. ${ }^{(16,17)}$

Methicillin-resistant Staphylococcus aureus (S. aureus) (MRSA) was initially considered a purely nosocomial pathogen. This changed significantly with the emergence and establishment of community-associated MRSA (CA-MRSA). ${ }^{(18)}$ Moreover, recent reports suggest that CA-MRSA is taking over healthcare-associated MRSA as a cause of endemic healthcare-acquired infections at many hospitals around the world. ${ }^{(19)}$

Other than in humans, these drug-resistant organisms have also been found in animals and the environment. ESBLproducing Enterobacteriaceae have been reported in livestock and wildlife. ${ }^{(20,21)}$ Reports of livestock-associated MRSA, which are genetically distinct from human isolates, have steadily increased. ${ }^{(18)}$ This is probably due to the overcrowded conditions of food animals in most commercial farms, along with extensive use of antibiotics as growth promoters, prophylaxis or metaphylaxis. ${ }^{(22)}$ The problem is exacerbated by the complicated exchange of antibiotic resistance genes between human, livestock and environmental pools, either via direct contact or through the food chain by contact with or ingestion of animal food products. ${ }^{(21}$

\section{Local perspective}

Multidrug-resistant organisms have also been reported in Singapore. The diversity in the epidemiology of these drugresistant organisms is likely the consequence of Singapore's strategic geographical location at international crossroads.

ESBL and AmpC beta-lactamase-producing Enterobacteriaceae were first documented in 1986 and 2003, respectively, in Singapore. ${ }^{(23,24)}$ In 2006, 30.3\% and $19.6 \%$ of hospital isolates of Klebsiella spp. and E. coli, respectively, were ESBL producers, with $5.6 \%$ and $8.5 \%$ of each type of bacteria also producing AmpC. ${ }^{(25)}$ These rates have remained relatively stable over the past decade in local hospitals. However, two dissimilar surveys in 2006 by Young et al and 2016 (Alex Cook et al, personal communication) showed a marked difference in community rectal carriage of ESBL-producing Enterobacteriaceae $(6.3 \%$ in 2006 vs. $26.0 \%$ in 2016), which appears to signify an increasing trend despite the differing methodology of the studies. ${ }^{(26)}$

Of greater concern is the growing threat of CRE. Rare in 2008, CRE was at that time due almost entirely to a combination of ESBL or AmpC beta-lactamases production combined with drug impermeability due to porin loss. ${ }^{(24)}$ The introduction of carbapenemase-producing Enterobacteriaceae (CP-CRE) - with diverse plasmid-borne enzymes such as NDM, KPC and OXA48-like variants - into local hospitals in rapid succession since
2010 has changed the local dynamic drastically. ${ }^{(27,28)}$ In a study conducted in Singapore General Hospital, the largest hospital in Singapore, carbapenem resistance rates among Klebsiella pneumoniae and E. coli increased from $2 \%$ and $0 \%$ to $12 \%$ and 5\%, respectively, between 2011 and 2015. ${ }^{(29)}$ From 2010 to 2013, NDM was the most frequently detected gene (57.3\%), followed by OXA-48-like (24.2\%) and KPC (13.7\%) genes, ${ }^{(30)}$ although the situation can change rapidly. Fortunately, CP-CRE rates appear to have stabilised in the past two years. ${ }^{(31)}$ Antibiotic resistance in non-fermenting Gram-negative bacteria is also of concern. From 2011 to 2015, the prevalence of carbapenem-resistant Acinetobacter baumannii and Pseudomonas aeruginosa has remained stable at approximately $50 \%$ and $10 \%$, respectively. ${ }^{(29)}$

MRSA emerged in Singapore in the 1970 s, ${ }^{(32)}$ becoming endemic in local healthcare facilities, with $35.3 \%$ of all $S$. aureus isolates reported to be methicillin-resistant in 2006. ${ }^{(33)}$ Apart from acute care hospitals, intermediate-term and long-term care facilities are also important reservoirs for MRSA. In 2014, the prevalence of MRSA was found to be significantly higher in intermediate (29.9\%) and long-term (20.4\%) care facilities than in acute care hospitals $(11.8 \%)$, as reported in a recent study. ${ }^{(34)}$ The organism has also been sporadically reported in the community as well as in local food and animals. ${ }^{(35-37)}$ The $\mathrm{MOH}$, working with public sector hospitals, has stepped up measures to track and control the rates of MRSA, which have since fallen considerably from over a decade ago. ${ }^{(38)}$ However, MRSA rates in private sector hospitals are not publicly available.

Vancomycin-resistant Enterococcus (VRE) was first reported in Singapore in 1994 but remained rare until two significant outbreaks in 2004 and 2005. ${ }^{(39)} \mathrm{A}$ passive laboratory surveillance programme from 2006 to 2010 concluded that $0.4 \%-0.7 \%$ of all clinical enterococcal isolates were resistant to vancomycin over these five years, with the overall incidence density of VRE remaining stable over time. ${ }^{(40)}$ Unfortunately, resistance to the few antibiotics with activity against VRE has started to emerge, and VRE carriage rates appear to have increased since $2010 .^{(41,42)}$

\section{LOCAL SURVEILLANCE}

In the human healthcare sector, the Network for Antimicrobial Resistance Surveillance (Singapore) - an informal collaboration between public sector clinical microbiologists, pharmacists and infectious diseases physicians that was established in 2005 was the first local multi-hospital group to elucidate the scale of antibiotic drug resistance and prescription in the local setting. ${ }^{(33)}$ Participation in this programme was voluntary, resulting in gaps in the data collected. The network published reports until 2011, several of which took the form of academic publications. ${ }^{(43-45)}$

In 2009, the $\mathrm{MOH}$ formally established the National Antimicrobial Taskforce (NAT) - consisting of infectious disease physicians, microbiologists, infection control physicians, nurses and pharmacists - to formulate and implement measures to monitor the use of antibiotics as well as AMR rates. The NAT was also tasked with recommending measures to prevent and limit the incidence of such infections. The NAT has published annual reports on public sector hospital AMR and antibiotic 
prescribing rates since 2012, but these are not publicly available. In 2014, the NAT was reorganised into the National Antimicrobial Resistance Control Committee (NARCC), for surveillance of AMR and antibiotic prescribing, and the National Infection Prevention and Control Committee, for providing national guidelines on infection prevention in the healthcare setting.

Surveillance on AMR and antimicrobial prescribing has been patchy in the animal and food sectors in Singapore. Academic projects implemented prior to 2018 were primarily independent and one-off. ${ }^{(35,46,47)}$ With the announcement of the National Strategic Action Plan against AMR, however, representatives of the $\mathrm{MOH}, \mathrm{AVA}, \mathrm{NEA}$ and PUB have made an effort to initiate AMR surveillance in the animal, food and environmental sectors, and this information will be incorporated into a joint 'One Health' report along with the NARCC annual reports in the near future.

\section{LOCAL RESEARCH}

Research is critical to fill in evidence gaps in AMR by generating new knowledge. This includes identifying risk factors for the emergence and spread of resistant organisms, and ways to stop their progress. This information will support relevant policymakers and organisations in making decisions on the appropriate actions necessary to combat AMR. There has been an increase in research activities and collaboration between various research groups in recent years, largely supported by the public sector in Singapore.

The National Research Foundation is currently funding a SGD 30-million research project in AMR over five years. ${ }^{(48)}$ This project, helmed by the Singapore-MIT Alliance for Research and Technology, is being conducted by an interdisciplinary research group (IRG) in partnerships with universities and research institutions in Singapore. ${ }^{(49)}$ The IRG seeks to identify new mechanisms of AMR to develop new drugs and drug delivery technologies, and to exploit host immunity to kill resistant microbes. It is also interested in developing new therapeutic diagnostic methods that are fast, cheap and easy to administer.

On a smaller scale, the National Medical Research Council (NMRC) is currently funding an SGD 5-million fouryear collaborative grant on AMR. ${ }^{(50)}$ The grant programme, Collaborative Solutions Targeting Antimicrobial Resistance Threats in the Health System (CoSTAR-HS), is a collaboration between three major hospitals in Singapore. CoSTAR-HS focuses on health systems and is looking to develop new diagnostic methods for identification of resistance mechanisms in microbes, new assessments for infection control strategies, optimisation of ASPs, and research into health systems and behavioural drivers of AMR. In addition to the above, multiple individual research grants have been given out by the NMRC, $\mathrm{MOH}$ and Agency for Science, Technology and Research for a variety of independent research efforts into AMR over the past decade.

Other than research on human health, it is also important to focus on animals, food and the environment. Although there is ongoing research in these sectors, much more work is needed to develop new vaccines, drugs, animal management systems and husbandry practices. ${ }^{(46,51)}$ In addition, there is a need to understand how antibiotics may contribute to the selection and spread of drug-resistant organisms in the natural environment. This information is necessary to better control the transmission of drug-resistant organisms between the human, animal, food and environment sectors.

One critical piece that is missing in Singapore is an estimate of the socioeconomic impact of AMR at the local level. While a number of macro- and microeconomic studies have been published, ${ }^{(2,6,52)}$ these do not include the unique features of our healthcare system nor our reliance on food importation; a more accurate local assessment would enable better financing estimates for the control of AMR in Singapore.

\section{EDUCATION ON ANTIMICROBIAL RESISTANCE AND ANTIBIOTIC PRESCRIBING}

As misconceptions about appropriate antibiotic use and the consequences of misusing antibiotics are common, ${ }^{(53)}$ education is needed to guide people towards a correct, unified understanding and perception of AMR, including its impact on society. Education serves two main purposes: (a) to let the target audience recognise that AMR is an urgent issue that needs to be acted upon; and (b) to equip them with the right knowledge to effectively participate in activities against AMR.

Education for healthcare and veterinary professionals should include appropriate antibiotic usage, contributors to AMR and infection control issues. These are currently included in the education curricula of many undergraduate and graduate healthcare professional programmes. Ongoing continuing education keeps professionals up to date as new evidence on AMR emerges. Training workshops can also be conducted. For example, in the area of antimicrobial stewardship, the annual Singapore Antimicrobial Stewardship Training introduces local and regional participants to best practices and skills that are needed to establish ASPs. ${ }^{(54)}$

In addition to knowledge and skills, promoting behavioural changes in practice is also important and should be guided by sociobehavioural understanding of the target audience. A local focus group study was conducted to explore hospital physicians' perceptions of and attitudes toward their ASP. ${ }^{(55)}$ Two reasons identified for poor acceptance of ASP recommendations were lack of awareness of the ASP team and lack of trust in them. These could potentially be addressed through improved communication with the various hospital departments via educational roadshows, regular reports on their antibiotic prescription trends, and published evidence that ASP recommendations specific to their department are advantageous to their patients. ${ }^{(56-60)}$

Patients' attitudes and expectations often influence physicians' antibiotic prescribing practices, ${ }^{(53)}$ reinforcing the need for public education to increase awareness about the issue of AMR and appropriate antibiotic use. Since 2016, Singapore has been actively participating in the annual World Antibiotic Awareness Week, supported by the WHO every November, by reaching out to the public at various public forums, hospitals and national libraries. ${ }^{(61,62)}$ In 2017, the $\mathrm{MOH}$ and Health Promotion Board organised a social campaign called F.I.G.H.T., focusing 
on the general prevention of infection to fight the spread of influenza and other infectious diseases. ${ }^{(63)}$ Most recently, the issue of antibiotics overprescription was featured in the local newspapers. ${ }^{(64,65)}$ The articles highlighted the results of a recent national point prevalence study (PPS) stating that more than half the patients in acute hospitals were on at least one antibiotic, a much higher proportion compared to inpatients in European hospitals. ${ }^{(66)}$

Emphasis should also be placed on education in the agriculture and biopharmaceutical sectors, although these are small in Singapore. End-users of veterinary medicines such as farmers should know how to responsibly use antibiotics in farm animals. Pharmaceutical industries, farms and hospitals involved in the disposal of waste should be educated on proper waste management to reduce the discharge of antibiotics into the environment, reinforced by local regulatory controls.

\section{PREVENTION AND CONTROL OF INFECTION IN SINGAPORE}

Effective infection prevention and control (IPC) measures are required to minimise infection risks and limit the emergence and spread of drug-resistant organisms among humans and animals, which ultimately reduces the usage of antibiotics. Vaccination is occasionally overlooked as an intervention against AMR. However, the prevention of viral or bacterial infections that could lead to healthcare visits correspondingly reduces opportunities for antibiotic prescription. In 2017, MOH established the National Adult Immunisation Schedule to facilitate the uptake of important vaccinations such as influenza and pneumococcal vaccines among adults. ${ }^{(67)}$ These recommendations are not mandatory, and measures to monitor and encourage vaccine uptake are necessary.

IPC programmes are mandated for all hospitals as part of hospital licensing. National guidelines for IPCs have recently been published by the National Infection Prevention and Control Committee and help to establish standards and guidance to prevent the spread of infections, including from multidrugresistant organisms. ${ }^{(68)}$ Hospitals must report infection control indicators routinely to the $\mathrm{MOH}$ for detection of any peculiar trends.

In the animal sector, the Singapore Food Agency (SFA) enforces strict biosecurity requirements and good animal husbandry/aquaculture practices to reduce the occurrence of infectious diseases in animals, although testing for multidrugresistant organisms in food is not routinely performed.

\section{OPTIMISATION OF ANTIMICROBIAL PRESCRIPTION AND USE}

\section{Community and veterinary prescription of antibiotics}

There remains a gap in knowledge about the amount and appropriateness of antibiotic prescribing in the primary healthcare setting in Singapore, although it is likely that improvements can be made. ${ }^{(53)}$ A similar gap exists for antibiotics prescribed in local veterinary and agricultural practices. In these settings, in addition to attempts to improve data capture, strategies to improve prescribing practices in the community - such as guidelines for antibiotic prescription and incentives to encourage proper antibiotic usage - should be developed to tackle the issue of inappropriate prescribing. The use of antibiotics in veterinary medicine could be governed by regulations, while guidelines would encourage the prudent use of antibiotics in livestock and veterinary medicine.

\section{Hospital antibiotic prescription}

Data from the acute care hospitals suggests that antibiotic usage is high: in a national PPS conducted in 2015, 51\% of 5,415 patients from 13 private and public acute hospitals were on at least one systemic antibiotic. ${ }^{(66)}$ This was significantly higher than comparable results from a global PPS that reported $37.2 \%$ and $39 \%$ in other Asian and European settings, respectively. ${ }^{(69)}$ The national study also found that $12.8 \%$ of the prescriptions were for surgical prophylaxis, the majority of which were prescribed for more than one day, a practice that is non-evidence-based. ${ }^{(66)}$ Unfortunately, appropriateness of antibiotic prescriptions was not assessed as it was beyond the scope of this national PPS, although public hospitals - such as KK Women's and Children's Hospital - have reported that broad-spectrum antibiotics such as carbapenems were appropriately prescribed up to $90 \%$ of the time. ${ }^{(70)}$

\section{Antimicrobial stewardship programmes in Singapore}

ASPs aim to optimise antibiotic use through multi-pronged strategies, including pre-authorisation, prospective audit with intervention and feedback, and, more recently, the use of computerised clinical decision support systems (CDSSs) to improve antibiotic prescribing at the time of prescribing. ${ }^{(71)}$ In 2011, MOH provided SGD 20 million to fund the development of ASPs in Singapore's public acute care hospitals. This fund was used for the provision of ASP teams - consisting of infectious diseases physicians, microbiologists, infectious diseases pharmacists and executives - as well as the development of CDSSs. Guidelines for training and practice of antimicrobial stewardship were introduced the year after in order to ensure a consistent standard of delivery. ${ }^{(72)}$

Since then, numerous studies from various institutions have reported that ASPs were able to improve the appropriateness of antibiotic prescriptions and reduce the duration of antibiotic use without compromising patient safety. ${ }^{(56-60)}$ Acceptance of ASP recommendations was associated with shorter lengths of stay, decreases in mortality and re-admissions, and substantial cost savings for patients, although ASPs on their own were notably unsuccessful in significantly decreasing the incidence of AMR in local hospitals. ${ }^{(73-75)}$

The first local CDSS, ARUS-C (Antibiotic Resistance Utilisation and Surveillance-Control), was developed by Tan Tock Seng Hospital in 2009, prior to MOH's ASP funding which spurred attempts to adopt ARUS-C or develop new CDSSs after 2011. ${ }^{(76)}$ By using appropriate algorithms, CDSSs could potentially provide patient-specific, evidence-based antibiotic recommendations at the point of prescribing, an advantage that is potentially magnified by the availability of other patient data 
within electronic medical records such as drug allergies, culture results, and renal and/or liver function.

Unfortunately, the CDSSs set up in Singapore had limited success in improving antibiotic prescribing: only $63 \%-67 \%$ of the antibiotic recommendations from the various CDSSs were accepted. ${ }^{(55,77)}$ Another attempt to adopt ARUS-C at another local hospital failed entirely, with the hospital's senior management pulling the plug after a short trial period. Understanding physician behaviour when using CDSS, integrating CDSS into the work process in a user-friendly manner and education on its proper usage are important to optimise uptake and acceptance.

Since 2011, ASPs have been implemented in all public acute care hospitals in Singapore. They have not been established in private hospitals and are present in only a couple of community hospitals.

\section{Future steps to optimise prescription in hospitals}

ASPs should ideally be established in both public and private hospitals, which might require a regulatory approach similar to that used for infection prevention programmes in Singapore. One possibility for established ASPs is to shift from antibiotic-specific audits to syndrome-specific audits. This is an effective way to improve prescribing, as the intervention message can be focused, with clinical guidelines and algorithms reinforced. ${ }^{(71)}$ Syndromespecific audits could then be regularly evaluated to identify new areas for targeted interventions based on local needs. ${ }^{(71)}$

The recently established National Collaborative Prescribing Programme trains experienced pharmacists and advanced practice nurses to legally prescribe medicines and order tests, without requiring a doctor's countersignature. ${ }^{(78)}$ This could possibly change the landscape of ASPs, with ASP pharmacists taking on a more active role to ensure appropriate antibiotic prescriptions or to order further investigations for the team.

New technology can be harnessed to improve patient care and the use of antibiotics. A National Electronic Health Records (NEHR) system, set up in 2011, has been collating patient health records across different healthcare providers. ${ }^{(79)}$ The NEHR allows healthcare professionals to have a holistic and longitudinal view of patients' healthcare histories. As the number of institutions participating in the NEHR increases, including general practitioner clinics, we can expect more seamless care for patients, as all previous laboratory and radiological investigations as well as prior antibiotic usage would be readily available. This enormous amount of data could potentially be harnessed for machine learning and artificial intelligence to identify potentially inappropriate prescriptions as well as improve prescribing via the development of superior versions of current-day CDSSs. ${ }^{(80,81)}$

\section{CONCLUSION}

AMR has gained considerable recognition as a major global public health threat. The position paper published in this journal a decade ago was limited in scope, focusing on human health and antibiotic prescribing in particular. A more nuanced understanding of AMR as a 'One Health' issue has emerged since then, and considerable work has gone into controlling AMR and improving antibiotic prescribing in Singapore, although this has been largely focused in the public hospital setting. The actual impact on the control of AMR has been mixed, with better control of MRSA coupled with a global rise in Gram-negative resistance that has also affected local hospitals and the community.

More efforts for AMR control are required in the human health, animal and environment sectors. These gaps are recognised in Singapore's National Strategic Action Plan against AMR, which has also led to the formation of a new entity - the AMR Coordinating Office based at the National Centre for Infectious Diseases - to track and coordinate national efforts.

Other potential future steps towards the control of AMR in Singapore include expanding surveillance and educational efforts directed towards the private healthcare sector, the community and the agricultural/veterinary sectors; improving vaccination rates and other aspects of IPC in hospitals and community; continued research funding, particularly for estimating the socioeconomic impact of AMR at the local level; improving the delivery of ASPs; and harnessing new technology, including artificial intelligence, to improve antibiotic prescribing.

Because AMR is an evolutionary process, the implementation of policies to control AMR as a 'One Health' effort similarly needs to continually evolve in order to maintain or improve on current gains. This will require persistently strong political will and a motivated workforce in Singapore.

\section{REFERENCES}

1. World Health Organization. Antimicrobial resistance: global report on surveillance. 2014. Available at: https://apps.who.int/iris/bitstream/ handle/10665/112642/9789241564748_eng.pdf?sequence=1. Accessed September 16, 2018.

2. O'Neill J. Tackling drug-resistant infections globally: final report and recommendations. The review on antimicrobial resistance. May 2016. Available at: https://amr-review.org/sites/default/files/160518_Final\%20paper_with\%20 cover.pdf. Accessed September 16, 2018.

3. World Health Organization. Global action plan on antimicrobial resistance. 2015. Available at: http://www.wpro.who.int/entity/drug_resistance/resources/ global_action_plan_eng.pdf. Accessed September 16, 2018.

4. United Nations General Assembly. Political declaration of the high-level meeting of the General Assembly on antimicrobial resistance. 2016. Available at: https:// digitallibrary.un.org/record/842813/files/A_71_L-2-EN.pdf. Accessed September 16, 2018.

5. Hsu LY, Kwa AL, Lye DC, et al. Reducing antimicrobial resistance through appropriate antibiotic usage in Singapore. Singapore Med J 2008; 49:749-55.

6. World Bank Group. Drug-resistant infections: a threat to our economic future (final report). March 2017. Available at: http://documents.worldbank.org/ curated/en/323311493396993758/pdf/114679-REVISED-v2-Drug-ResistantInfections-Final-Report.pdf. Accessed September 16, 2018.

7. Agri-Food \& Veterinary Authority of Singapore, Ministry of Health, National Environment Agency, National Water Agency. The national strategic action plan on antimicrobial resistance, Singapore. 2017. Available at: https://www.moh. gov.sg/docs/librariesprovider5/resources-statistics/reports/sg-national-strategicaction-plan-on-amr.pdf. Accessed September 16, 2018.

8. World Health Organization. Countries step up to tackle antimicrobial resistance. Available at: https://www.who.int/news-room/detail/18-07-2018-countries-stepup-to-tackle-antimicrobial-resistance. Accessed September 16, 2018.

9. World Health Organization. Global monitoring of country progress on antimicrobial resistance (AMR): Country self-assessment questionnaire (version two). Available at: https://amrcountryprogress.org/download/AMR-selfassessment-country-questionnaire-2017-English.pdf. Accessed September 16, 2018.

10. World Health Organization. Global database for antimicrobial resistance country self assessment. Available at: https://amrcountryprogress.org. Accessed September 16, 2018.

11. Vasoo S, Barreto JN, Tosh PK. Emerging issues in gram-negative bacterial resistance: an update for the practicing clinician. Mayo Clin Proc 2015; 90:395-403. 
12. McDanel J, Schweizer M, Crabb V, et al. Incidence of extended-spectrum $\beta$-lactamase (ESBL)-producing Escherichia coli and Klebsiella infections in the United States: a systematic literature review. Infect Control Hosp Epidemiol 2017; 38:1209-15.

13. Karanika S, Karantanos T, Arvanitis M, Grigoras C, Mylonakis E. Fecal colonization with extended-spectrum beta-lactamase-producing Enterobacteriaceae and risk factors among healthy individuals: a systematic review and metaanalysis. Clin Infect Dis 2016; 63:310-8.

14. Hawkey PM. Multidrug-resistant Gram-negative bacteria: a product of globalization. J Hosp Infect 2015; 89:241-7.

15. Hsu LY, Apisarnthanarak A, Khan E, et al. Carbapenem-resistant Acinetobacte baumannii and Enterobacteriaceae in South and Southeast Asia. Clin Microbiol Rev 2017; 30:1-22.

16. Liu YY, Wang Y, Walsh TR, et al. Emergence of plasmid-mediated colistin resistance mechanism MCR-1 in animals and human beings in China: a microbiological and molecular biological study. Lancet Infect Dis 2016; 16:161-8.

17. Wang R, van Dorp $L$, Shaw $L P$, et al. The global distribution and spread of the mobilized colistin resistance gene MCR-1. Nat Commun 2018; 9:1179.

18. Lakhundi S, Zhang K. Methicillin-resistant Staphylococcus aureus: molecular characterization, evolution, and epidemiology. Clin Microbiol Rev 2018; 31:e00020-18.

19. Otter JA, French GL. Nosocomial transmission of community-associated methicillin-resistant Staphylococcus aureus: an emerging threat. Lancet Infect Dis 2006; 6:753-5.

20. Okpara EO, Ojo OE, Awoyomi OJ, et al. Antimicrobial usage and presence of extended-spectrum $\beta$-lactamase-producing Enterobacteriaceae in animal-rearing households of selected rural and peri-urban communities. Vet Microbiol 2018; 218:31-9

21. Dolejska M, Papagiannitsis CC. Plasmid-mediated resistance is going wild. Plasmid 2018; 99:99-111.

22. Graveland H, Duim B, van Duijkeren E, Heederik D, Wagenaar JA. Livestockassociated methicillin-resistant Staphylococcus aureus in animals and humans. Int J Med Microbiol 2011; 301:630-4.

23. Inglis TJ, Kumarasinghe G, Chow C, Liew HY. Multiple antibiotic resistance in Klebsiella spp. and other Enterobacteriaceae isolated in Singapore. Singapore Med J 1994; 35:602-4.

24. Koh TH. Gram-negative resistance in Singapore: a historical perspective. Ann Acad Med Singapore 2008; 37:847-54.

25. Tan TY, Hsu LY, Koh TH, et al. Antibiotic resistance in gram-negative bacilli: a Singapore perspective. Ann Acad Med Singapore 2008; 37:819-25.

26. Young BE, Lye DC, Krishnan P, Chan SP, Leo YS. A prospective observational study of the prevalence and risk factors for colonization by antibiotic resistant bacteria in patients at admission to hospital in Singapore. BMC Infect Dis 2014; $14: 298$.

27. Teo J, Ngan G, Balm M, et al. Molecular characterization of NDM-1 producing Enterobacteriaceae isolates in Singapore hospitals. Western Pac Surveill Response J 2012; 3:19-24.

28. Balm MN, Ngan G, Jureen R, Lin RT, Teo JW. OXA-181-producing Klebsiella pneumoniae establishing in Singapore. BMC Infect Dis 2013; 13:58.

29. Teo JQ, Cai Y, Lim TP, Tan TT, Kwa AL. Carbapenem resistance in Gram-negative bacteria: the not-so-little problem in the little red dot. Microorganisms 2016; 4:E13.

30. Teo JW, Tan P, La MV, et al. Surveillance trends of carbapenem-resistant Enterobacteriaceae from Singapore, 2010-2013. J Glob Antimicrob Resist 2014; 2:99-102.

31. Marimuthu K, Venkatachalam I, Khong WX, et al; Carbapenemase-Producing Enterobacteriaceae in Singapore (CaPES) Study Group. Clinical and molecular epidemiology of carbapenem-resistant Enterobacteriaceae among adult inpatients in Singapore. Clin Infect Dis 2017; 64(suppl_2):S68-S75.

32. Esuvaranathan K, Kuan YF, Kumarasinghe G, Bassett DC, Rauff A. A study of 245 infected surgical wounds in Singapore. J Hosp Infect 1992; 21:231-40.

33. Hsu LY, Tan TY, Jureen $R$, et al. Antimicrobial drug resistance in Singapore hospitals. Emerg Infect Dis 2007; 13:1944-7.

34. Chow A, Lim VW, Khan A, et al. MRSA transmission dynamics among interconnected acute, intermediate-term, and long-term healthcare facilities in Singapore. Clin Infect Dis 2017; 64(suppl_2):S76-S81.

35. Aung KT, Hsu LY, Koh TH, et al. Prevalence of methicillin-resistant Staphylococcus aureus (MRSA) in retail food in Singapore. Antimicrob Resist Infect Control 2017; 6:94.

36. Hsu LY, Koh YL, Chlebicka NL, et al. Establishment of ST30 as the predominant clonal type among community-associated methicillin-resistant Staphylococcus aureus isolates in Singapore. J Clin Microbiol 2006; 44:1090-3.

37. Sergio DM, Koh TH, Hsu LY, et al. Investigation of meticillin-resistant Staphylococcus aureus in pigs used for research. J Med Microbiol 2007; 56(Pt 8):1107-9.

38. Philomin L. Hospitals step up measures to curb 'superbug' that spreads via touch. TODAY 2015 Nov 1. Available at: https://www.todayonline.com/singapore/ hospitals-step-measures-curb-superbug-spreads-touch. Accessed October 23, 2018.
39. Chlebicki MP, Kurup A. Vancomycin-resistant enterococcus: a review from a Singapore perspective. Ann Acad Med Singapore 2008; 37:861-9.

40. Cai Y, Chan JP, Fisher DA, et al. Vancomycin-resistant Enterococci in Singaporean hospitals: 5-year results of a multi-centre surveillance programme. Ann Acad Med Singapore 2012; 41:77-81.

41. Chow A, Win NN, Ng PY, Lee W, Win MK. Vancomycin-resistant enterococci with reduced daptomycin susceptibility in Singapore: prevalence and associated factors. Epidemiol Infect 2016; 144:2540-5.

42. Tan D, Htun HL, Koh J, et al. Comparative epidemiology of vancomycinresistant enterococci colonization in an acute-care hospital and its affiliated intermediate- and long-term care facilities in Singapore. Antimicrob Agents Chemother 2018; 62:e01507-18.

43. Hsu LY, Tan TY, Tam VH, et al; Network for Antimicrobial Resistance Surveillance (Singapore). Surveillance and correlation of antibiotic prescription and resistance of Gram-negative bacteria in Singaporean hospitals. Antimicrob Agents Chemother 2010; 54:1173-8.

44. Teo J, Tan TY, Hon PY, et al; Network for Antimicrobial Resistance Surveillance (Singapore). ST22 and ST239 MRSA duopoly in Singaporean hospitals: 20062010. Epidemiol Infect 2013; 141:153-7.

45. Liew $Y X$, Krishnan $P$, Yeo CL, et al; Network for Antimicrobial Resistance Surveillance Singapore. Surveillance of broad-spectrum antibiotic prescription in Singaporean hospitals: a 5-year longitudinal study. PLoS One 2011; 6:e28751.

46. Hartantyo SHP, Chau ML, Fillon L, et al. Sick pets as potential reservoirs of antibiotic-resistant bacteria in Singapore. Antimicrob Resist Infect Control 2018; 7:106.

47. Chau ML, Chen SL, Yap M, et al. Group B streptococcus infections caused by improper sourcing and handling of fish for raw consumption, Singapore, 20152016. Emerg Infect Dis 2017; 23:1982-90.

48. Hio L. $\$ 83 \mathrm{~m}$ boost to help S'pore tackle challenges. The Straits Times 2017 Dec 2. Available at: https://www.straitstimes.com/singapore/83m-boost-to-helpspore-tackle-challenges. Accessed October 1, 2018.

49. Singapore-MIT Alliance for Research and Technology. Antimicrobial resistance interdisciplinary research group. Available at: https://smart.mit.edu/research/ amr/about-amr. Accessed October 1, 2018.

50. Saw Swee Hock School of Public Health. Collaborative solutions targeting antimicrobial resistance threats in the health system (CoSTAR-HS). Available at: https://sph.nus.edu.sg/research/costar-hs/. Accessed July 3, 2019

51. Lim EJ, Ho SX, Cao DY, et al. Extended-spectrum beta-lactamase-producing Enterobacteriaceae in retail chicken meat in Singapore. Ann Acad Med Singapore 2016; 45:557-9.

52. Founou RC, Founou LL, Essack SY. Clinical and economic impact of antibiotic resistance in developing countries: a systematic review and meta-analysis. PLoS One 2017; 12:e0189621.

53. Pan DS, Huang JH, Lee MH, et al. Knowledge, attitudes and practices towards antibiotic use in upper respiratory tract infections among patients seeking primary health care in Singapore. BMC Fam Pract 2016; 17:148.

54. Tan Tock Seng Hospital. Singapore antimicrobial stewardship training course. 2017. Available at: https://www.ttsh.com.sg/page.aspx?id=11478. Accessed October 5, 2018.

55. Chua AQ, Tang SSL, Lee LW, et al. Psychosocial determinants of physician acceptance toward an antimicrobial stewardship program and its computerized decision support system in an acute care tertiary hospital. J Am Coll Clin Pharm 2018; 1:e1-e8.

56. Liew YX, Lee W, Loh JC, et al. Impact of an antimicrobial stewardship programme on patient safety in Singapore General Hospital. Int J Antimicrob Agents 2012; 40:55-60.

57. Loo LW, Liew YX, Lee W, Chlebicki P, Kwa AL. Impact of antimicrobial stewardship program (ASP) on outcomes in patients with acute bacterial skin and skin structure infections (ABSSSIs) in an acute-tertiary care hospital. Infect Dis Ther 2015; 4(Suppl 1):15-25

58. Cai Y, Shek PY, Teo I, et al. A multidisciplinary antimicrobial stewardship programme safely decreases the duration of broad-spectrum antibiotic prescription in Singaporean adult renal patients. Int J Antimicrob Agents 2016; 47:91-6.

59. Teng CB, Ng TM, Tan MW, et al. Safety and effectiveness of improving carbapenem use via prospective review and feedback in a multidisciplinary antimicrobial stewardship programme. Ann Acad Med Singapore 2015; 44:19-25.

60. Seah XF, Ong YL, Tan SW, et al. Impact of an antimicrobial stewardship program on the use of carbapenems in a tertiary women's and children's hospital, Singapore. Pharmacotherapy 2014; 34:1141-50.

61. Hsu LY. The campaign for global antibiotic awareness. TODAY 2016 Nov 7. Available at: https://www.todayonline.com/daily-focus/health/campaign-globalantibiotic-awareness. Accessed October 5, 2018.

62. Choy CY, Hsu LY. World antibiotic awareness week. Ann Acad Med Singapore 2017; 46:413-4.

63. Health Promotion Board. Fight the spread of infectious diseases. Available at: https://www.healthhub.sg/programmes/52/Fight_The_Spread. Accessed October 5, 2018. 
64. Hsu LY. Doctors here too eager to prescribe antibiotics. The New Paper 2018 Oct 2. Available at: https://www.tnp.sg/news/singapore/doctors-here-too-eagerprescribe-antibiotics. Accessed October 5, 2018.

65. Khalik S. Hospital patients at risk of catching an infection. The Straits Times 2018 Oct 2. Available at: https://www.straitstimes.com/singapore/hospital-patientsat-risk-of-catching-an-infection. Accessed October 5, 2018.

66. Cai Y, Venkatachalam I, Tee NW, et al. Prevalence of healthcare-associated infections and antimicrobial use among adult inpatients in Singapore acute-care hospitals: results from the first national point prevalence survey. Clin Infect Dis 2017; 64(suppl_2):S61-S67.

67. Ministry of Health Singapore. $\mathrm{MOH}$ establishes national adult immunisation schedule; extends use of medisave for vaccines under the schedule. 21 Oct 2017. Available at: https://www.moh.gov.sg/news-highlights/details/moh-establishesnational-adult-immunisation-schedule-extends-use-of-medisave-for-vaccinesunder-the-schedule. Accessed February 9, 2019

68. Ministry of Health Singapore. The national infection prevention and contro guidelines for acute healthcare facilities 2017. Available at: https://www.moh. gov.sg/docs/librariesprovider5/resources-statistics/guidelines/national-infectionprevention-and-control-guidelines-for-acute-healthcare-facilities---2017.pdf. Accessed February 9, 2019

69. Versporten A, Zarb P, Caniaux I, et al; Global-PPS network. Antimicrobial consumption and resistance in adult hospital inpatients in 53 countries: results of an internet-based global point prevalence survey. Lancet Glob Health 2018 ; 6:e619-e629.

70. KK Women's and Children's Hospital. Carbapenem appropriateness in KKH. Available at: https://www.kkh.com.sg/about-kkh/corporate-profile/carbapenemappropriateness. Accessed November 4, 2018.

71. Barlam TF, Cosgrove SE, Abbo LM, et al. Implementing an antibiotic stewardship program: guidelines by the Infectious Diseases Society of America and the Society for Healthcare Epidemiology of America. Clin Infect Dis 2016; 62:e51-77.
72. Teng CB, Lee $W$, Yeo CL, et al. Guidelines for antimicrobial stewardship training and practice. Ann Acad Med Singapore 2012; 41:29-34.

73. Ng TM, Phang VY, Young B, et al. Clinical impact of non-antibiotic recommendations by a multi-disciplinary antimicrobial stewardship team. Int J Antimicrob Agents 2017; 50:166-70.

74. Lew KY, Ng TM, Tan M, et al. Safety and clinical outcomes of carbapenem de-escalation as part of an antimicrobial stewardship programme in an ESBLendemic setting. J Antimicrob Chemother 2015; 70:1219-25.

75. Liew YX, Lee W, Kwa AL, Chlebicki MP. Cost effectiveness of an antimicrobial stewardship programme. Int J Antimicrob Agents 2015; 46:594-5.

76. Chow AL, Ang A, Chow CZ, et al. Implementation hurdles of an interactive, integrated, point-of-care computerised decision support system for hospital antibiotic prescription. Int J Antimicrob Agents 2016; 47:132-9.

77. Chow A, Lye DC, Arah OA. Psychosocial determinants of physicians' acceptance of recommendations by antibiotic computerised decision support systems: a mixed methods study. Int J Antimicrob Agents 2015; 45:295-304.

78. Baker JA. Experienced public healthcare sector pharmacists, nurses to be allowed to prescribe medicines from July. Channel NewsAsia 2018 Mar 7. Available at: https://www.channelnewsasia.com/news/singapore/experienced-publichealthcare-sector-pharmacists-nurses-to-be-10021468. Accessed November $4,2018$.

79. IHiS. National Electronic Health Record (NEHR). Available at: https://www.ihis. com.sg/nehr/about-nehr. Accessed November 4, 2018.

80. Beaudoin M, Kabanza F, Nault V, Valiquette L. Evaluation of a machine learning capability for a clinical decision support system to enhance antimicrobial stewardship programs. Artif Intell Med 2016; 68:29-36.

81. Sethi T, Maheshwari S, Nagori A, Lodha R. Stewarding antibiotic stewardship in intensive care units with Bayesian artificial intelligence. Wellcome Open Res $2018 ; 3: 73$ 


\section{SINGAPORE MEDICAL COUNCIL CATEGORY 3B CME PROGRAMME} (Code SMJ 201908A)

1. Antibiotic-resistant bacteria in livestock and the environment have no impact on human health.

2. Human activity and antibiotic use have been the most important factors contributing to the issue of antimicrobial resistance today.

3. The impact of antimicrobial resistance at the global level, if left unchecked, has been estimated at several million deaths each year by the year 2050, with a financial cost equivalent to the 2008 financial crisis.

4. There is universal acceptance at the country level that action against antimicrobial resistance is critical and necessary.

5. There is ongoing and regularly updated global surveillance on the prevalence of antibiotic prescription and antibiotic-resistant bacteria in all countries.

6. Methicillin-resistant Staphylococcus aureus has now been identified in both the community setting and in animals in Singapore.

7. Extended-spectrum beta-lactamase-producing Enterobacteriaceae have not yet emerged as a cause of community-acquired infections in Singapore.

8. The antibiotic-resistant bacteria currently of greatest concern in Singapore hospitals is carbapenemresistant Enterobacteriaceae.

9. The incidence of infections caused by carbapenem-resistant Pseudomonas aeruginosa ( $P$. aeruginosa) has increased over the past few years in Singapore hospitals, with more than $30 \%$ of $P$. aeruginosa clinical isolates being resistant to carbapenems.

10. Vancomycin-resistant enterococci are currently the most prevalent antibiotic-resistant bacteria causing drug-resistant infections in Singapore.

11. The socioeconomic impact of antimicrobial resistance in Singapore has been calculated and is used to guide policies to control the issue here.

12. Better infection control policies, including good hand hygiene, are key to preventing the spread of antibiotic-resistant bacteria in the hospital setting.

13. Infection control programmes are mandated as part of hospital licensing for both public and private hospitals in Singapore.

14. Antibiotic stewardship programmes are mandated in Singapore hospitals as part of hospital licensing by the Ministry of Health.

15. The Singapore Food Agency (former the Agri-Food and Veterinary Authority of Singapore) reinforces good animal husbandry practices but does not routinely test livestock products for antibiotic-resistant bacteria.

16. Influenza and pneumococcal vaccinations may reduce antibiotic prescription at the population level.

17. Patients' attitudes and expectations may influence physicians' antibiotic prescription preferences, and represent an area where more efforts can be made to reduce antibiotic-seeking behaviour.

18. The use of computerised decision support systems to provide recommendations to physicians prescribing antibiotics has been universally accepted in Singapore hospitals.

19. Acceptance of antibiotic stewardship recommendations in Singapore public hospitals has generally been associated with positive patient outcomes.

20. Antibiotic stewardship programmes have significantly reduced the incidence of drug-resistant infections in Singapore hospitals.

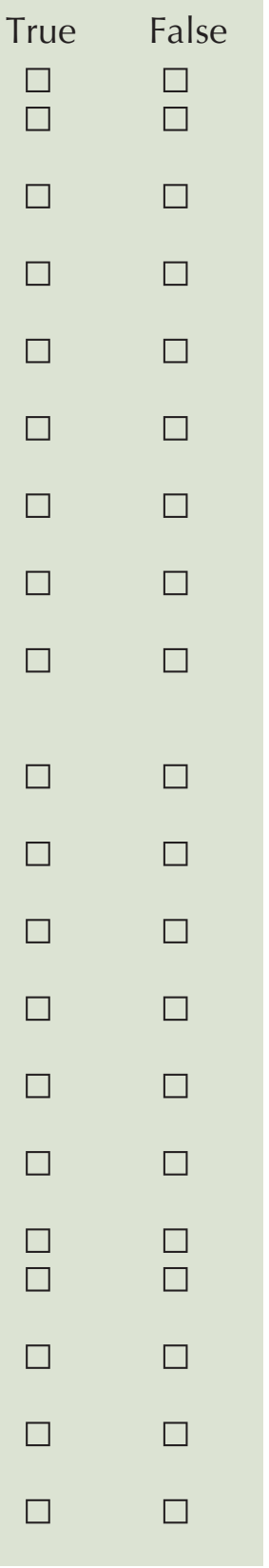

\section{Doctor's particulars:}

Name in full:

MCR no.:

Specialty:

Email:

\section{SUBMISSION INSTRUCTIONS}

Visit the SMJ website: http://www.smj.org.sg/current-issue and select the appropriate quiz. You will be redirected to the SMA login page.

For SMA member: (1) Log in with your username and password (if you do not know your password, please click on 'Forgot your password?'). (2) Select your answers for each quiz and click 'Submit'.

For non-SMA member: (1) Create an SMJ CME account, or log in with your SMJ CME username and password (for returning users). (2) Make payment of SGD 21.40 (inclusive of $7 \%$ GST) via PayPal to access this month's quizzes. (3) Select your answers for each quiz and click 'Submit'.

RESULTS:

(1) Answers will be published online in the SMJ October 2019 issue. (2) The MCR numbers of successful candidates will be posted online at the SMJ website by 10 October 2019. (3) Passing mark is $60 \%$. No mark will be deducted for incorrect answers. (4) The SMJ editorial office will submit the list of successful candidates to the Singapore Medical Council. (5) One CME point is awarded for successful candidates. (6) SMC credits CME points according to the month of publication of the CME article (i.e. points awarded for a quiz published in the December 2017 issue will be credited for the month of December 2017, even if the deadline is in January 2018).

Deadline for submission (August 2019 SMJ 3B CME programme): 12 noon, 3 October 2019. 